Occupational injury research

\title{
Occupational injury research at NOIRS 2003
}

\section{J Howard}

\section{Third National Occupational Injury Research Symposium}

n October 2003, the National Institute for Occupational Safety and Health (NIOSH), and its co-sponsors, the National Safety Council, the American Society of Safety Engineers and Liberty Mutual Center for Safety Research, hosted the Third National Occupational Injury Research Symposium-NOIRS 2003. NOIRS 2003 brought together the foremost researchers in occupational injury to present their latest scientific findings and methods and is the third such symposium focusing on research for the prevention of work related traumatic injuries.

The occurrence of sudden physical injury at work-whether fatal or nonfatal, whether permanently or partially disabling, whether from explosion, or from adverse involvement with moving machinery, or from fire, the effects of gravity, the inappropriate release of electrical, chemical or nuclear energy, human generated violence, structural or earthen collapse, an excess of man made or solar heat-and how we can prevent such occupational injuries, was the purpose of NOIRS 2003.

If we look back to the first Occupational Injury Research Symposium in October 1997, and compare where occupational injury prevention is in 2003, three important changes are evident.

First, there was an increased focus in 2003 on the safety of emergency response workers. At the 1997 symposium, there was only one presentation on emergency responder safety, but at last year's symposium, there were a total of 17 presentations and posters addressing emergency responder safety and four full sessions on the topic. This increased focus is due in large part to a 1998 Fire Fighter Initiative in which Congress allocated funding to the Institute to investigate fire fighter fatalities, and to the events of 11 September 2001.

Second, there was an increased focus on occupational motor vehicle traffic safety. At the 1997 symposium, there were only two presentations providing data on occupational motor vehicle crashes. In contrast, at last year's symposium, there were 11 presentations and posters, including two sessions on the topics of motor vehicle safety and transportation injuries. In fact, the Institute has launched a significant, new research and intervention program addressing occupational motor vehicle related fatal and non-fatal injury prevention. Also, the Institute has just published a Hazard Review on WorkRelated Roadway Crashes.'

Third, at the 2003 symposium, there was an increased focus on highway construction workzone safety. There was one presentation related to workzones in 1997-last year there were five presentations and one special session. The Institute also has a significant research and intervention program underway addressing highway workzone safety.

What has been the progress since the 1997 NOIRS in reducing traumatic injuries among American workers? The impact of occupational injury research and prevention efforts is evidenced by the reduction of fatal work injuries across the American workforce-an $11 \%$ overall decline since 1997. In fact, total fatal injuries in 2002 declined 6.6\% over $2.1 \%$ - the lowest ever recorded by the fatality census since its inception in 1992. ${ }^{2}$

In 2002, fatal highway accidents were down $3 \%$ from 2001, but continued to be the most frequent type of fatal workplace event in 2002, accounting for about a quarter of all fatal work injuries. Workplace homicides were down about 5\% in 2002 and fatalities resulting from falls declined for the first time since 1998, from 810 in 2001 to 714 in 2002, a drop of $12 \%$. Construction continued to record the highest number of fatal injuries of any major industry, although the total for construction was down $9 \%$ from the series high recorded in 2001. ${ }^{2}$ However, some things since 1997 have remained fairly static.

Most of the high risk industries, worker populations, and injury causes that were priority areas for occupational injury prevention research in 1997 are still with us today, exacting a still unacceptable toll in worker lives' lost or permanently disabled and employers experiencing productivity losses.
Even though fatal injuries among Latino workers - which had been rising each year since 1995-were down about $6 \%$ from 2001 to 2002 , the 840 fatal work injuries recorded for Latino workers in 2002 accounted for the second highest annual total for that population. $^{2}$

Many Latinos are recent immigrants to the United States and represent a transforming force in the American workforce. In general, immigrants tend to have lower educational attainment, greater poverty, and less income than the native born, non-immigrant population. Over a third of all unskilled jobs are now held by immigrants and about half of the foreign born population in the United States is from Latin America. The Latino population represented $9 \%$ of the American population in 1990, by 2000 the representation of Latinos had grown to $12.5 \%$ and by 2050 , it is predicted that Latinos will represent one out of every four persons in the United States. ${ }^{3}$

Latino men and women are more likely to be employed than non-Latino workers in riskier blue collar and service occupations, such as farm workers, janitors, construction laborers, cooks, groundskeepers, and gardeners. Surveillance data show that racial and ethnic minorities suffer disproportionately from both fatal and non-fatal work related injuries and illnesses.

Latino workforce safety is a national issue. Data from the 2000 United States census tells us that the challenges in occupational safety and health are not limited to those states traditionally associated with large Latino populations-such as California, Texas, New York, and Florida. Rather, the challenge of developing culturally integrated approaches to workplace safety will impact numerous other states not traditionally known for large Latino populations_-such as North Carolina, Arkansas, Georgia, Tennessee, Nevada, South Carolina, Alabama, Kentucky, Minnesota, and Nebraska. These 10 states showed anywhere from a $150 \%$ to a $350 \%$ increase in their Latino populations between the 1990 and 2000 censuses. $^{4}$

The 2000 census data point to a major challenge that the entire occupational injury prevention research community still faces-bridging the gap between research findings and the implementation of evidence based, culturally competent, prevention practices in workplaces in the United States.

In the context of a public health approach to injury prevention research, more effort is needed to "close the loop" and translate and implement the findings of injury prevention research in 
workplaces in the United States. Three points are important to mention.

First, there needs to be an increase in intervention evaluation. We need to improve the balance between the generation of new knowledge and interventions and the evaluation of that knowledge and those interventions in the workplace. Ascertaining or fixing the value or worth of injury prevention interventions-making a judgment whether an intervention is effective in reducing injury risk-is critical to determining whether an intervention should be introduced widely, continued, modified, or eliminated from a safety program. Evaluation is critical to making sure that we are using our scarce resources to maximal effect-the ultimate economic question that intervention evaluation poses to all of us.

Second, we need to establish effective partnerships. For a partnership to be effective, it needs to be based on a complete-scientific and economicunderstanding of industrial processes and operations, including cost related data, needs to include access to worksites and workers populations, needs to foster industry and workers' input in the planning of research studies, needs to ensure industry participation in review of study designs and reports and in evaluations and intervention demonstrations at the actual workplace and, finally, it needs to ensure ways to disseminate results of research and to implement effective results more broadly throughout an industrial sector.

Third, we need to increase implementation of our research into practice through vigorous research and technology transfer. Traumatic injury-as opposed to other adverse health events with lengthy pre-event periods during which secondary or tertiary prevention efforts can positively affect the outcome-occurs in a timeframe that leaves little time to discuss, plan, and implement prevention methods once the chain of injury causation is triggered.

On 25 March 1911, as workers were getting ready to leave for the day, a fire broke out in the Triangle shirtwaist factory in New York's Greenwich Village. In only 30 minutes, 146 people died. They died in just 30 minutesfrom fire or from a fall-an intentional fall-from the ninth floor of the building that still stands on the corner of Greene Street and Washington Place. ${ }^{5}$ Similarly, on 11 September 2001, 2886 workers died from fire, an intentional fall, or structural collapse-also, all within a short period of time. Trauma changes us and moves us in new directions-after the Triangle shirtwaist factory fire in 1911, many dramatic social and political changes occurred in New York City and around the country, including improvements in emergency response and workplace fire safety and the adoption of workers' compensation legislation in New York State.

And, now, just two years after the events of September 11th, all of us are the midst of similar changes. Since September 11th, the Institute itself has been engaged in at least several new workplace preparedness areas-advancing the design, selection, and appropriate use of respirators that can be relied on to protect workers against chemical, biologic, radiological, and nuclear agents in physically demanding conditions of use; studying the feasibility of incorporating sensor technology into respirators; investigating and applying new methods for environmental sampling of bioterrorism agents; developing guidelines to protect occupants of offices, retail facilities, schools, and other buildings from chemical, biologic, radiological, and nuclear attacks through greater attention to a building's ventilation systems; and monitoring the health of World Trade Center workers and volunteers.

Finally, traumatic injuries change us and move us in new directions. For example, even though the word trauma is Greek for "wound," not all traumatic injury is physical in nature. In the 19th century, thanks to the birth of psychoanalysis, the word trauma came to be applied to psychic injury. And, indeed, the psychic injuries that accompanied the traumatic injuries of September 11th-as well as the psychic component of all traumatic injuriesneed more attention by occupational injury researchers.

$\mathrm{NIOSH}$, in association with its private and public partners, was pleased to host NOIRS 2003 to provide a forum for workplace injury researchers to share their work with other researchers, but, most importantly, to share research results with practitioners. This issue of Injury Prevention, highlighting papers presented at NOIRS 2003, is an additional step in that direction. NIOSH is most interested in ensuring that the roads from research to practice are well paved, clearly marked, and heavily trafficked. In doing so, the American worker and the American employer greatly benefit from the investment that the American taxpayer continues to make in the vitally important field of occupational traumatic injury research.

Injury Prevention 2004;10:195-196.

doi: 10.1136/ip.2004.005413

Correspondence to: Dr John Howard, National Institute for Occupational, Safety and Health, Hubert H Humphrey Bldg, Room 717H, 200 Independence Ave, SW, Washington, DC 20201, USA; jhoward1@cdc.gov

\section{REFERENCES}

1 National Institute for Occupational Safety and Health. NIOSH hazard review: work-related roadway crashes: challenges and opportunities for prevention, NIOSH Publication No 2003-119. Washington, DC: US Department of Health and Human Services, 2003.

2 Bureau of Labor Statistics. Census of fatal occupational injuries (CFOI). Washington, DC: US Department of Labor, 2002.

3 US Census. 2000 census. Washington, DC: US Department of Commerce, 2001.

4 Richardson S, Ruser J, Suarez P. Hispanic workers in the United States: an analysis of employment distribution, fatal occupational injuries and non-fatal occupational injuries and illnesses. Safety is seguridad: a workshop summary. National Research Council of the National Academies. Washington, DC: National Academies Press, 2003:43-72.

5 Schaefer A. The Triangle shirtwaist factory fire. New York, NY: World Almanac Library, 2003:1-6 